\title{
Isolated Gall Bladder Perforation in A Tertiary Care Hospital in Eastern Nepal: A Descriptive Cross-sectional Study
}

Brikh Raj Joshi, ${ }^{1}$ Swotantra Gautam, ${ }^{2}$ Saroj Adhikari Yadav, ${ }^{3}$ Sushil Dhakal, ${ }^{4}$ Rasmita Thapaliya, ${ }^{5}$ Rakesh Kumar Gupta ${ }^{6}$

'Department of Surgery, Lumbini Provincial Hospital, Butwal, Rupendehi, Nepal, ${ }^{2}$ B. P. Koirala Institute of Health Sciences, Dharan, Nepal, ${ }^{3}$ Patan Academy of Health Sciences, Patan, Nepal, ${ }^{4}$ Department of Pathology, Maya Metro Hospital, Dhangadi, Nepal, ${ }^{5}$ Department of Nursing, Sanjievani College of Medical Sciences, Rupendehi, Nepal, ${ }^{6}$ Department of Surgery, B. P. Koirala Institute of Health Sciences, Dharan, Nepal.

\section{ABSTRACT}

Introduction: Cholelithiasisis is a common surgical problem worldwide. Gall bladder perforation is a rare life-threatening complication with considerable mortality. This study aims to find the etiology, demography, type of perforation, and outcome of gall bladder perforation.

Methods: This descriptive cross-sectional study was done on patients above 18 years of age visiting department of surgery of B. P. Koirala Institute of Health Sciences (BPKIHS) who were diagnosed with isolated gall bladder perforation. The study was done from 1st January 2006 till 30 December 2016. Ethical approval was obtained from the Institutional Research Committee (reference number. 34/074/075). The convenient sampling method was used. Data were entered in excel sheets and analyzed.

Results: Out of 49 patients included in the study, 28 (57.14\%) were females and the commonest age group was 36 to 50 years 22 (44.9\%) followed by 51 to 65 years 16 (32.6\%). Most of the patients presented in emergency with pain in their abdomen. Diabetes mellitus was the commonest co-morbidity present in $10(20.41 \%)$ patients. Operative management was done in $45(91.84 \%)$ of the patient and conservative management in $4(8.16 \%)$. After surgery of 45 patients, $43(95.56 \%)$ improved and 2 (4.44\%) expired. The most common type of perforation was Niemeier Type I in 21 (46.67\%) followed by Type III 14 (31.11\%). The most common histopathological diagnosis was acute cholecystitis 20 $(44.44 \%)$.

Conclusions: Isolated gall bladder perforation is not an uncommon complication. The most common etiological factor was acute cholecystitis with a slight female predominance. Most of the patients needed surgical intervention and they had good outcomes when diagnosed and managed on time.

Keywords: cholecystitis; classification; gallbladder; perforation.

\section{INTRODUCTION}

Gallbladder perforation (GBP) is a rare life-threatening condition. Cholelithiasis is a common surgical problem worldwide. GBP is a rare complication of different gallbladder disease. ${ }^{1}$ Common etiological factors include cholecystitis, gall bladder carcinoma, traumatic perforation, etc. Most cases of GBP can only be diagnosed during surgery. ${ }^{2}$

Because of delays in diagnosis, there is high morbidity and mortality. Thus, GBP continues to be an important problem for surgeons. ${ }^{3,4}$ The mortality rate of GBP ranges from 12 to $42 \% .^{2,5}$ Niemeier in 1934, classified
GBP into three types, viz, Type I-acute perforation into the free peritoneal cavity and generalized biliary peritonitis, Type II-subacute perforation with abscess formation and localized peritonitis; and Type IIIchronic perforation with fistula formation between the gallbladder and another viscus. ${ }^{6}$

After an extensive literature search, we found scarcity in studies regarding the GBP. This study aims to

Correspondence: Dr. Swotantra Gautam, B. P. Koirala Institute of Health Sciences, Dharan, Nepal. Email: bpkihs.gautam@ gmail.com, Phone: +977-9841769467. 
find out the etiology, patient demography, type of perforation, and outcome of GBP.

\section{METHODS}

This study was conducted in the department of surgery of B. P. Koirala Institute of Health Sciences (BPKIHS), Dharan, Nepal. Record sheets of the patients who had isolated GBP were retrieved. The study included all the patients above 18 years of age, admitted as a case of isolated GBP from 1st January 2006 till 30 December 2016 (11 years). Ethical approval was taken from the Institutional Research Committee of BPKIHS (Ref No. Acad. 34/074/075). Records with grossly incomplete data were excluded from the study. Convenient sampling was done.

Sample size was calculated as,

$\mathrm{n}=\mathrm{Z}^{2} \times \mathrm{p} \times(1-\mathrm{p}) / \mathrm{e}^{2}$

$=(1.96)^{2} \times 0.5 \times(1-0.5) /(0.14)^{2}$

$=49$

where,

$\mathrm{n}=$ Sample size

$\mathrm{Z}=1.96$ at $95 \%$ Confidence Interval

$\mathrm{p}=$ population proportion, $50 \%$

$\mathrm{e}=$ margin of error, $14 \%$

Thus a total of 49 samples were included in this study. Patients presenting in the emergency with features of peritonitis (generalized) were planned for emergency exploratory laparotomy after all the preoperative investigation. Written consent was taken from the patient and patient relative. After general anesthesia and endotracheal intubation prepping and draping of the operative site were done. A generous midline incision was made and rectus sheath was incised with the help of electric cautery. The peritoneum was opened, bilious fluid was sucked and peritoneal lavage was done with normal saline. Intraoperative findings were noted. Either anterograde or retrograde cholecystectomy was performed according to intraoperative findings. Hemostasis was secured and an intraabdominal drainage tube of $28 \mathrm{Fz}$ was kept in the right subhepatic space. Rectus sheath was closed with polypropylene number 1 suture and skin was closed with nylon 3-0 sutures.

In elective cases, after general anesthesia and endotracheal intubation prepping and draping were done. Pneumoperitoneum was created by open (Hasson's) technique. The thirty-degree telescope was inserted and then three working ports were made (10 $\mathrm{mm}$ port 3 to $5 \mathrm{~cm}$ below xiphisternum, $5 \mathrm{~mm}$ port 2 to $3 \mathrm{~cm}$ below right subcostal margin in midclavicular line and5 $\mathrm{mm}$ port in anterior axillary line 3 to $4 \mathrm{~cm}$ below the costal margin). Then the patient was kept in a reverse Trendelenburg position and fifteen degrees left tilt. Gallbladder fundus was retracted toward the right shoulder and intraoperative findings were noted. If there was evidence of fistula between gallbladder and gastrointestinal tract (cholecystogastric, cholecystoduodenal, or cholecystocolic fistula) then the procedure was converted to open cholecystectomy. Right subcostal incision (Kocher's incision) was made. Muscles were divided and the peritoneum was opened. Intraoperative findings were noted and management was done according to intraoperative findings. Generally, the fistulous tract was excised and the hollow viscus defect was closed with polyglactin suture 3-0 round body needle.

Data were collected in predesigned proforma regarding the demographic profile, clinical presentation, general physical examination, per abdominal examination, positive findings on systemic examinations, investigations (Ultrasonography (USG), X-ray abdomen, contrast-enhanced computed tomography (CECT) abdomen), type of management done (conservative or surgical and type of surgery) and histopathological reports. Data were entered in an excel sheet and converted into Statistical Package for the Social Sciences software (SPSS) version 11.5 for statistical analysis. The data were presented in number and percentage.

\section{RESULTS}

Out of 49 patients, 28 (57.14\%) were females and 21 $(42.86 \%)$ were males. The most common age group affected was 36 to 50 years of age 22 (44.90\%) followed by 51 to 65 years of age group 16 (32.65\%) (Figure 1).

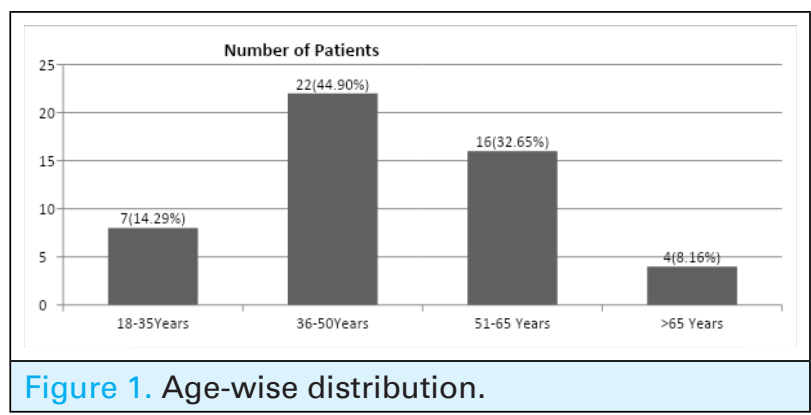

Among them, $31(63.27 \%)$ patients presented in the emergency and $18(36.73 \%)$ in OPD (Outpatient Department). All the patients had abdominal pain. Fever was present in 25 (51.02\%). Only 5 (10\%) patients had a history of abdominal trauma. Most of the patients $32(65.31 \%)$ had no comorbidities. Comorbidities associated were diabetes mellitus in 10 $(20.41 \%)$, hypertension 4 (8.16\%), steroid use 2 (4.08\%), and chronic obstructive pulmonary disease (COPD) 1 (2.04\%). Abdominal ultrasonography was done in 47 $(95.92 \%)$ of the patient but the diagnosis of GBP was made by USG in only $3(6.12 \%)$ patients (Table 1$)$. 
Joshi et al. Isolated Gall Bladder Perforation in A Tertiary Care Hospital in Eastern Nepal: A Descriptive Cross-sectional Study

\begin{tabular}{|c|c|c|}
\hline Findings & Variables & n (\%) \\
\hline \multirow{2}{*}{ Presented at } & OPD & $18(36.73)$ \\
\hline & Emergency & $31(63.27)$ \\
\hline \multirow{2}{*}{ Abdominal Pain } & Localized & $28(57)$ \\
\hline & Generalized & $21(43)$ \\
\hline \multirow{2}{*}{ Fever } & Yes & $25(51)$ \\
\hline & No & $24(49)$ \\
\hline \multirow{2}{*}{ Abdominal trauma } & Yes & $5(10)$ \\
\hline & No & $44(90)$ \\
\hline \multirow{4}{*}{ Abdominal findings } & Tenderness & $41(37.3)$ \\
\hline & Guarding & $30(27.3)$ \\
\hline & $\begin{array}{l}\text { Rebound } \\
\text { tenderness }\end{array}$ & $30(27.3)$ \\
\hline & Normal & $9(8.2)$ \\
\hline \multirow{5}{*}{ Comorbidities } & No Comorbidities & $32(65.31)$ \\
\hline & Diabetes Mellitus & $10(20.41)$ \\
\hline & Hypertension & $4(8.16)$ \\
\hline & Steroid Use & $2(4.08)$ \\
\hline & COPD & $1(2.04)$ \\
\hline
\end{tabular}

The majority of patients, i.e. 45 (91.84\%) received operative treatment and $4(8.16 \%)$ were managed by conservative treatment. Total mortality was $6(12.24 \%)$. All four patients managed conservatively. Among 45 surgically managed patients, 43 (95.56\%) improved and 2 (4.44\%) expired (Table 2 ).

\begin{tabular}{|llll|}
\hline \multicolumn{4}{|c|}{ Table 2. Treatment and outcome $(\mathrm{n}=49)}$. \\
\hline Management & $\begin{array}{l}\text { Frequency } \\
\mathrm{n}(\%)\end{array}$ & $\begin{array}{l}\text { Outcome } \\
\text { Improved } \\
\mathrm{n}(\%)\end{array}$ & $\begin{array}{l}\text { Expired } \mathrm{n} \\
(\%)\end{array}$ \\
Conservative & $4(8.16)$ & 0 & $4(100)$ \\
Operative & $45(91.84)$ & $43(95.56)$ & $2(4.44)$ \\
Total & $49(100)$ & $43(87.76)$ & $6(12.24)$ \\
\hline
\end{tabular}

Among the 45 patients treated operatively, the most common site of GBP was fundus 33 (73.33\%). $21(46.47 \%)$ of patients had Niemeier Type I, 10 (22.22\%) had Type II and 14 (31.11\%) had Niemeier Type III GBP. According to histopathological report, the most common etiology for GBP was acute cholecystitis 20 (44.44\%), followed by acute on chronic cholecystitis 12 (26.67\%), chronic cholecystitis $9(20 \%)$, adenocarcinoma of the gallbladder 3 (6.67\%), and Salmonella typhi infection in $1(2.22 \%)$ (Table 3$)$.
Table 3. Site and type of perforation of 45 operatively managed patients $(n=45)$.

\begin{tabular}{|lll|}
\hline Observations & Variable & $\begin{array}{l}\text { Frequency } n \\
(\%)\end{array}$ \\
Site of perforation & Body & $12(26.67)$ \\
\cline { 2 - 3 } $\begin{array}{l}\text { Type of } \\
\text { Perforation }\end{array}$ & Fundus & $33(73.33)$ \\
& Niemeier type I & $21(46.67)$ \\
Histopathological & Niemeier type III & $14(31.11)$ \\
Diagnosis & $\begin{array}{l}\text { Acute } \\
\text { Cholecystitis }\end{array}$ & $20(44.44)$ \\
& $\begin{array}{l}\text { Cholecystitis } \\
\text { Cholecystitis }\end{array}$ & $12(26.67)$ \\
& $\begin{array}{l}\text { Adenocarcinoma } \\
\text { of GB }\end{array}$ & $3(6.67)$ \\
& Salmonella Typhi & $1(2.22)$ \\
\hline
\end{tabular}

\section{DISCUSSION}

In this study, we found that GBP was slightly more predominant in females $57.14 \%$ than males $42.86 \%$. But a study done by Derici, Stefanidis, and Ergul found that males were having more perforation than females $\left(62.5 \%, 76.7 \%\right.$, and $54.1 \%$ respectively). ${ }^{6-8}$ This contradiction may be because of more prevalence of gall stone in females in our set up and so the complications.

Abdominal ultrasonography was done in $95.92 \%$ of the patients but the only diagnosis was made by USG in only $6.12 \%$ of the patients. This may be because of the low-resolution ultrasound scanner. Sood, et al. reported that the sonographic hole sign is the only reliable sign of gallbladder perforation and was only visible by a high-resolution ultrasound scanner device in $70 \%$ of patients. ${ }^{2}$ In our study only a few patients underwent computed tomography (CT) scan of the abdomen due to either unavailability or unaffordability of abdominal CT in an emergency.

As much as $91.84 \%$ of patients received operative treatment in the form of open cholecystectomy or laparotomy with cholecystectomy and $8.16 \%$ were managed conservatively. Conservative treatment was done for patients who were unfit for surgery. Conservative treatment was done by percutaneous abdominal drain placement in subhepatic space, fluid and electrolyte supplement, and intravenous antibiotics (both aerobic and anaerobic coverage). All the patients under conservative treatment expired probably due to multiple comorbid conditions like diabetes mellitus, chronic respiratory disease, sepsis, septic shock, and multiple organ dysfunctions. 
Among surgically 45 managed patients, most of the patients were managed with open operation rather than laparoscopically. This is probably because of surgeon preference and due to technical difficulties for the repair of a fistula between the gallbladder and hollow viscuslaparoscopically.

Mortality in our study was $12.24 \%$, however, there were only two mortalities among 45 operated cases and all four patients under conservative treatment died. Anderson BB also reported that ultimately cholecystectomy was mandatory for the definitive treatment of GBP. ${ }^{9}$ Due to a lack of imaging modality, the mortality was as high as $40 \%$ in the past. But now it came down to 10 to $12 \% .{ }^{11}$ Glenn and Moore have reported that the mortality rate in patients with gallbladder perforation was $42 \% .^{5}$ Whereas, other studies reported that the mortality rates have decreased to $12 \%-16 \%$ owing to the developments in anesthesiology and intensive care conditions. ${ }^{7}$ Higher percentage of mortality in our study was due to delay in diagnosis and treatment as well as the nature of the disease, comorbidities, and complications like sepsis, septic shock, and multi-organ dysfunctions.

In this study, the most common etiology was acute cholecystitis $44.44 \%$ followed by acute on chronic cholecystitis $26.67 \%$, chronic cholecystitis $20 \%$. Other studies too showed cholecystitis as the commonest etiology for GBP.,11-13 The etiology was adenocarcinoma of the gallbladder in $6.66 \%$ in our study but adenocarcinoma is not reported as a common cause of GBP in other studies. ${ }^{6-8,11-13}$

We found that the most common site of GBP was fundus $67.35 \%$ of the gall bladder because it is the most remote area concerning blood supply as described by Roslyn J. ${ }^{10}$ In this study we found that $46.67 \%$ of patients had Niemeier Type I, 22.22\% had Type II and $31.11 \%$ had Type III GBP.

\section{CONCLUSIONS}

Isolated GBP is not an uncommon complication in our tertiary care center. The most common etiological factor was acute cholecystitis with a slightly female predominance. Niemeier Type I was the commonest type of perforation. Most of the patients needed surgical intervention and had a good outcome when diagnosed and managed on time.

\section{ACKNOWLEDGEMENTS}

We would like to thank the Department of Surgery, Department of Pathology, nursing staff, and medical record section for their constant support to conduct this study.

\section{Conflict of Interest: None.}

\section{REFERENCES}

1. Jones DB, Dunnegan DL, Soper NJ. The influence of intraoperative gallbladder perforation on long-term outcome after laparoscopic cholecystectomy. Surg Endosc. 1995;9:977. [PubMed | Full Text | DOI]

2. Sood BP, Kalra N, Gupta S, et al. Role of sonography in the diagnosis of gallbladder perforation. J Clin Ultrasound. 2002;30:270-4. [uㅏㄹed | Full Text | DOI]

3. Roslyn JJ, Thompson JE, Darvin H, Den BL. Risk factors for gallbladder perforation. Am J Gastroenterol. 1987;82:636-40. [PubMed]

4. OW Niemeier. Acute free perforation of the gallbladder. Ann Surg. 1934 Jun;99(6):922-4. [ [

5. Glenn F, Moore SW. Gangrene and perforation of the wall of the gallbladder. A sequele of acute cholecystitis. Arch Surg. 1942;44:677-86. [Full Text | DOI]

6. H Derici, C Kara, AD Bozdag, O Nazli, T Tansug, E Akca. Diagnosis and treatment of gallbladder perforation. World J Gastroenterol. 2006;12(48):7832-6. [PubMed | Full Text | $\underline{\mathrm{DOI}}]$
7. D Stefanidis, KR Sirinek, J Bingener. Gallbladder perforation: risk factors and outcome. J Surg Res. 2006;131(2):204-8. [PubMed | Full Text | DOI]

8. Ergul E, Gozetlik EO. Perforation of gallbladder. Bratisl LekListy. 2008;109(5):210-4. [pubMed]

9. Anderson BB, Nazem A. Perforations of the gallbladder and cholecystobiliary fistulae: a review of management and a new classification. J Natl Med Assoc. 1987,79:393-9. [PubMed]

10. Roslyn J, Busuttil RW. Perforation of the gallbladder: a frequently mismanaged condition. Am J Surg. 1979;137(3):307-12. [PubMed | Full Text | DOI]

11. F. Lennon, W.E. Green, Perforation of the gall bladder. A review of 32 cases. J R Coll Surg Edinb. 1983;28(3):169-73. [PubMed]

12. Wig JD, Chowdhary A, Talwar BL. Gall bladder perforations. Aust N Z J Surg. 1984;54(6):531-4. [uㅏMed | Full Text | DOl]

13. Menakuru SR, Kaman L, Behera A, Singh R, KatariyaRN. Current management of gall bladder perforations. ANZ J Surg. 2004;74(10):843-6. [uued | Full Text | DOI]

This work is licensed under a Creative Commons Attribution 4.0 International License. The images or other third party material in this article are included in the article's Creative Commons license, unless indicated otherwise in the credit line; if the material is not included under the Creative Commons license, users will need to obtain permission from the license holder to reproduce the material. To view a copy of this license, visit http://creativecommons.org/licenses/by/4.0/ 